\title{
Renal response to tunicamycin-induced endoplasmic reticulum stress in BDNF heterozygous mice
}

\author{
Selma Cirrık ${ }^{1, A-F}$, Gulay Hacioglu ${ }^{2, A-E}$, Sema Nur Ayyildız ${ }^{3, B-D}$, Berna Tezcan ${ }^{4, B-D}$, \\ İsmail Abidin ${ }^{5, B-E}$, Selcen Aydın-Abidin ${ }^{5, B-E}$, Tevfik Noyan ${ }^{3, B, C}$ \\ ${ }^{1}$ Faculty of Medicine, Department of Physiology, Ordu University, Turkey \\ 2 Faculty of Medicine, Department of Physiology, Giresun University, Turkey \\ ${ }^{3}$ Faculty of Medicine, Department of Medical Biochemistry, Ordu University, Turkey \\ ${ }^{4}$ Faculty of Medicine, Department of Histology and Embryology, Giresun University, Turkey \\ ${ }^{5}$ Faculty of Medicine, Department of Biophysics, Karadeniz Technical University, Trabzon, Turkey
}

A - research concept and design; $\mathrm{B}$ - collection and/or assembly of data; $\mathrm{C}$ - data analysis and interpretation; $D$ - writing the article; $E$ - critical revision of the article; $F$ - final approval of the article

\section{Address for correspondence}

Selma Cırrık

E-mail: selmacrrk@yahoo.com

\section{Funding sources}

This study was financially supported by Ordu University Research Funds (BAP, AR1664).

\section{Conflict of interest}

None declared

\section{Acknowledgements}

The authors would like to thank Prof. Dr. Hasan Sevgili for technical support in measuring total protein in the tissue homogenates.

Received on August 14, 2017

Reviewed on December 31, 2017

Accepted on December 11, 2018

Published online on August 20, 2019

Cite as

Cırrık S, Hacioglu G, Ayyıldız SN, et al. Renal response to tunicamycin-induced endoplasmic reticulum stress in BDNF heterozygous mice. Adv Clin Exp Med. 2019;28(9):1161-1170. doi:10.17219/acem/100647

DOI

10.17219/acem/100647

\section{Copyright}

Copyright by Author(s)

This is an article distributed under the terms of the Creative Commons Attribution Non-Commercial License (http://creativecommons.org/licenses/by-nc-nd/4.0/)

\begin{abstract}
Background. The protective effects of brain-derived neurotrophic factor (BDNF) against endoplasmic reticulum (ER) stress in neuronal tissue and endometrial cells have been reported.

Objectives. The aim of this study was to determine whether endogenously produced BDNF protects the kidneys against tunicamycin-induced (Tm) ER stress.

Material and methods. Brain-derived neurotrophic factor heterozygous knockout mice $\left(\mathrm{BDNF}^{(+-)}\right)$and their wild-type (WT) littermates were used. The animals were divided into 4 groups: WT, BDNF ${ }^{(+-)}$, WT+Tm, and BDNF(+ ${ }^{+-)}+\operatorname{Tm}$ ( $\mathrm{n}=7$ in each group). After 3 days of saline or $T \mathrm{~m}$ injection $(0.5 \mathrm{mg} / \mathrm{kg}$; intraperitoneally (i.p.)), renal BDNF, glucose-regulated protein 78 (GRP78), and caspase-12 levels as well as serum BDNF concentration were measured with enzyme-linked immunosorbent assay (ELISA). In the kidney sections, hematoxylin \& eosin (H\&E) staining, GADD153 immunostaining and TUNEL staining were performed. Serum creatinine levels were measured as an indicator of renal function.
\end{abstract}

Results. Circulating and tissue BDNF levels were significantly lower in the BDNF $F^{(+-)}$and $\mathrm{BDNF}^{(+/)}+\mathrm{Tm}$ groups. Renal levels of GRP78 and caspase-12, apoptotic index, and GADD153 staining were significantly higher in the WT+Tm and BDNF(+-) + Tm groups. However, apoptosis was more pronounced in the $B D N F^{(+/)}+T m$ group than in the WT+Tm group ( $p<0.01$ ). Similarly, GADD153 staining was more pronounced in the BDNF(+/-) + Tm group than in the WT+Tm group $(p<0.05)$. Tm caused a mild deterioration in the kidney tissue of the WT+Tm group, while general deterioration, pyknotic nuclei and swollen cells were observed in the BDNF(+-) + Tm group. Serum creatinine concentrations were significantly higher in the WT+Tm $(p<0.05)$ and BDNF(+ ${ }^{+-}+\operatorname{Tm}(p<0.05)$ groups.

Conclusions. This study showed that endogenous BDNF may play a protective role in kidneys against ER stress-induced apoptosis via the suppression of GADD153. As a result, BDNF and related signaling pathways could be considered for therapeutic/protective approaches in kidney disorders.

Key words: apoptosis, endoplasmic reticulum stress, kidney, BDNF heterozygous mice, GADD153 


\section{Introduction}

The endoplasmic reticulum (ER) is a multifunctional organelle necessary for the folding and processing of nascent proteins, the synthesis of cholesterol, steroids and other lipids, as well as for calcium storage. The protein folding capacity of the ER is impaired under different physiological and pathological conditions which induce ER stress. ${ }^{1,2}$ During ER stress, unfolded proteins which accumulate in the ER lumen trigger an adaptive cell response, called unfolded protein response (UPR), in order to maintain cell homeostasis. ${ }^{2,3}$ As an ER resident chaperone, glucose-regulated protein 78 (GRP78) recognizes unfolded proteins and plays an important role in the regulation of UPR through the activation of 3 pathways: PKRlike ER kinase (PERK), activated transcription factor 6 (ATF6) and inositol-requiring enzyme 1 (IRE1). Activation of UPR pathways first results in the global attenuation of protein synthesis and prevents any further accumulation of unfolded proteins. Upregulation of chaperones such as GRP78 and GRP94, which improve ER folding capacity, and upregulation of the ER-associated degradation system, which activates the degradation of misfolded proteins, are 2 other major adaptive responses. ${ }^{1-3}$ Despite these defense mechanisms, ER stress can trigger apoptosis, depending on the severity and duration of stress. Transcriptional activation of the C/EBP homologous protein (CHOP) - also known as a growth arrest or the DNA damage-inducible gene 153 (GADD153) - as well as activation of the cJUN NH2-terminal kinase (JNK) pathway and activation of ER-associated caspase-12, are involved in ER stress-mediated apoptosis. ${ }^{4,5}$ Endoplasmic reticulum stress-induced apoptosis and tissue injury have been implicated in various diseases, including neurodegenerative diseases such as Alzheimer's, Parkinson's and Huntington's diseases, ischemia-reperfusion injury, diabetes, and atherosclerosis. ${ }^{6-9}$

As a trophic factor, brain-derived neurotrophic factor (BDNF) promotes neuronal development, differentiation and survival in the central and peripheral nervous systems. ${ }^{10}$ Although it was originally discovered in brain tissue, the expression of BDNF and its main receptor - tropomyosin-related kinase $B(\operatorname{TrkB})$ - have been found in different non-neuronal tissues such as the heart, kidney, liver, lungs, skeletal muscle, blood vessels, adipose tissue, and prostate..$^{11-13}$ In addition to its well-known neuroprotective effects, BDNF participates in the regulation of energy metabolism, mood, blood pressure, and angiogenesis. Plasma levels of BDNF have been shown to be reduced in patients with type 2 diabetes, acute coronary syndrome, major depressive syndrome, and chronic kidney disease. ${ }^{14-17}$ The protective effect of BDNF against ER stress-induced apoptosis has been reported in neuronal cells as well as in endometrial epithelial cells. ${ }^{18-20}$ It has been suggested that the suppression of CHOP and/or caspase-12 activation may play important role in BDNF-mediated neuroprotection during ER stress. ${ }^{18,19}$

Though the expression of BDNF and the Trk receptor has been shown in kidneys, ${ }^{13,21,22}$ there is little knowledge available about the physiological roles of BDNF on glomerular or tubular functions. However, in vitro and in vivo studies have shown that exogenous administration of BDNF inhibits podocyte damage and prevents the glomerular lesions and proteinuria associated with adriamycin nephropathy. ${ }^{21}$ Recently, Kurajoh et al. have demonstrated that patients with chronic kidney disease have reduced plasma BDNF concentration and suggested that plasma BDNF level is a predictor of chronic kidney disease. ${ }^{17}$ These findings indicate the protective role of BDNF in normal kidney physiology. However, it remains unclear whether BDNF protects the kidneys against ER stress. Since ER stress is associated with various renal pathologies, such as diabetic nephropathy, idiopathic focal segmental glomerulosclerosis, membranous nephropathy, and minimal change disorders, we believe that answering this question will be valuable in elucidating the mechanisms of these renal pathophysiological states. ${ }^{23-27}$ For this purpose, the effects of reduced endogenous concentrations of BDNF on ER stress-induced kidney damage was examined both in physiological and tunicamycin-induced conditions. Brain-derived neurotrophic factor heterozygous mice were used because they are characterized by reduced BDNF expression. The results of the BDNF heterozygous mice and their wild-type littermates were compared.

\section{Material and methods}

\section{Animals}

In the present study, we used a transgenic mouse model originally established by Korte et al. ${ }^{28}$ In heterozygous knockout mice, 1 allele of the BDNF coding region is replaced by a neomycine-resistance gene $\left(\mathrm{BDNF}^{(+-)}\right)$, which results in completely viable, fertile and BDNF-deficient animals. Male $\mathrm{BDNF}^{+/-}$mice aged 6 to 8 months and their wild-type littermates (as control) were used in current study. The presence of the transgene in each subject was confirmed with polymerase chain reaction (PCR) analysis of tail tissue as described in earlier studies. ${ }^{29}$ All experiments were approved by the Local Institutional Animal Care and Use Committee of the Faculty of Medicine, Karadeniz Technical University, Trabzon, Turkey.

\section{Groups}

The animals were divided into 4 groups ( $\mathrm{n}=7$ in each group): wild-type (WT), wild-type mice injected with tunicamycin (WT+Tm), BDNF heterozygous $\left(\mathrm{BDNF}^{(+/-)}\right)$, and BDNF heterozygous mice injected with tunicamycin $\left(\mathrm{BDNF}^{(+/-)}+\mathrm{Tm}\right)$. 


\section{Tunicamycin injection}

The endoplasmic reticulum stress was induced with tunicamycin (Tm, Sigma-Aldrich T7765; Sigma-Aldrich, St. Louis, USA), which inhibits N-glycosylation in ER. ${ }^{18,20,30,31}$ A single dose of $\operatorname{Tm}(0.5 \mathrm{mg} / \mathrm{kg})$ was injected intraperitoneally (i.p.) in the $\mathrm{WT}+\mathrm{Tm}$ and $\mathrm{BDNF}^{(+/)}+\mathrm{Tm}$ groups, while the same volume of saline solution was given i.p. as a vehicle in the $\mathrm{WT}$ and $\mathrm{BDNF}^{(+-)}$groups. Three days after Tm or saline injection, the animals were sacrificed and blood and tissue samples were harvested. The blood samples were allowed to clot for $1 \mathrm{~h}$ at room temperature and then centrifuged at $1,000 \times \mathrm{g}$ for $15 \mathrm{~min}$. Serum samples were used for creatinine and BDNF measurements. For histological and immunohistochemical analysis, the right kidney was fixed in $10 \%$ neutral formalin. The left kidneys taken from the animals were homogenized in ice-cold PBS and then centrifuged at $5,000 \times$ g for $5 \mathrm{~min}$. The supernatants were used for enzyme-linked immunosorbent assay (ELISA) measurements.

\section{Serum creatinine measurement}

Serum creatinine levels were measured spectrophotometrically as described in previous research. ${ }^{32}$

\section{Measurements of serum BDNF levels}

The circulating BDNF levels in the serum samples were measured with a commercial ELISA kit (E-EL-M0203; Elabscience Biotechnology, Wuhan, China), according to the manufacturer's instructions. Prior to analysis, the samples were diluted (1:2) and added to the appropriate micro ELISA plate wells which were pre-coated with an antibody specific to mouse BDNF. The absorbance of the resulting yellow product was measured at a wavelength of $450 \mathrm{~nm}$ with a microplate reader (BioTek ELx800 brand REF ELX508 SN1310149; Thermo Fisher, Waltham, USA). The concentrations of BDNF in the samples were calculated by comparing the optical density (OD) of the samples to the standard curve and multiplying by the dilution factor.

\section{Measurements of renal BDNF, GRP78 and caspase- 12 levels}

In tissue homogenates, BDNF, GRP78 and caspase-12 levels were assayed using the appropriate ELISA kits (E-EL-M0203, Elabscience Biotechnology; E-EL-M2696, Elabscience Biotechnology; and E0781Mo, Bioassay Technology Laboratory, Shanghai, China, respectively). The analyses were performed according to the manufacturer's instructions and read using an absorbance microplate reader (BioTek ELx800). BDNF, GRP78 and caspase-12 levels were expressed as the proportion of total protein, which was determined with the Breadford method (ThermoFisher; 23200).

\section{Histological evaluations}

The kidney tissues were quickly fixed in 10\% neutral formalin. Routine hematoxylin \& eosin (H\&E) staining was applied to sections $5 \mu \mathrm{m}$ in thickness from paraffin blocks, following tissue attachment and paraffin embedding procedures, in order to reveal the structure of the tissues. GADD153 and TUNEL staining were also performed.

\section{TUNEL assay}

The detection of apoptotic cells in renal tissue slides was performed using an In Situ Apoptosis Detection Kit (ab206386; Abcam, Cambridge, UK), according to the manufacturer's instructions. First, deparaffinization and rehydration procedures were performed on the paraffin tissue sections. Then, the proteinase $\mathrm{K}$ digestion method was used to unmask the antigens. After treatment with TdT Equilibration Buffer, the TdT labeling reaction mix was applied at $37^{\circ} \mathrm{C}$. Following treatment with stop buffer and blocking buffer, $1 \mathrm{X}$ Conjugate and DAB solutions were used. All sections were contrasted with methyl green. The TUNEL-positive cells in the tissue sections were counted under a light microscope at a $\times 40$ magnification by randomly selecting 5 areas from each section. Cell death was reported as the percentage of TUNEL-positive cells vs total cells (apoptotic index).

\section{GADD153 immunuhistochemistry}

GADD153 was detected in paraffin-embedded tissues using an immunoperoxidase technique. The kidney sections were deparaffinized in xylene and rehydrated through graded alcohols to water. Antigen retrieval was performed with citrate buffer ( $\mathrm{pH}$ 6.0) in a microwave oven. All subsequent staining incubation steps were done at room temperature, and Tris-buffered saline $(\mathrm{pH} 7.4)$ was used for all washes and diluents. The slides were thoroughly washed after antibody incubation and were blocked with protein blocking solution for $15 \mathrm{~min}$. Then, primary antibody for mouse GADD153 (Santa Cruz Biotechnology, Santa Cruz, USA) was added to the slides at 1:100 dilution and they were incubated overnight. A biotinylated link antibody plus streptavidin-horseradish peroxidase kit (ThermoFisher) was applied, along with a 3-amino9-ethylcarbazole (AEC) chromogen and peroxide substrate to detect the labeled antibodies. The slides were counterstained with Mayer's hematoxylin and cover slipped with an aqueous mounting medium. The image analysis included the calculation of positive staining (intensity) area per section at $\times 40$ magnification and was carried out with Image J software v. 1.46r. For each image, the immunolabeled tissue area was determined, normalized by the total tissue area, and presented as a percentage of total tissue cross-sectional area. 


\section{Statistical analysis}

All data is given as mean \pm standard deviation (SD). Statistical analysis was performed with one-way analysis of variance (ANOVA) and Tukey's post-hoc tests using Graphpad Prism v. 4.0 software (Graphpad Software, San Diego, USA). Correlations were analyzed using Pearson's correlation analysis. Values of $\mathrm{p}<0.05$ were considered statistically significant.

\section{Results}

In animals injected with Tm, weight loss was observed 3 days after the injection. Body weight decreased from $23.1 \pm 2.3 \mathrm{~g}$ to $19.9 \pm 1.7 \mathrm{~g}$ and from $25.3 \pm 2.8 \mathrm{~g}$ to $20.7 \pm 2.0 \mathrm{~g}$ in the $\mathrm{WT}+\mathrm{Tm}$ and $\mathrm{BDNF}^{(+/)}+\mathrm{Tm}$ groups, respectively. These changes in body weight were not statistically significant.

\section{BDNF level in serum and kidney}

Serum BDNF levels were significantly lower among the $\mathrm{BDNF}^{(+/)}$mice $(0.14 \pm 0.04 \mathrm{ng} / \mathrm{mL})$ than the wild-type group $(0.22 \pm 0.02 \mathrm{ng} / \mathrm{mL} ; \mathrm{p}<0.01)$. As seen in Fig. $1 \mathrm{~A}, \mathrm{Tm}$ injection did not cause a significant change in serum BDNF levels, and the difference between wild-type and heterozygous subjects was preserved (WT+Tm vs $\mathrm{BDNF}^{(+/-)}+\mathrm{Tm}$; $\mathrm{p}<0.05)$. The BDNF levels in kidney tissue were markedly lower among the BDNF heterozygous animals, and were not affected by Tm injection (Fig. 1B).

\section{GRP78 level in kidney}

The concentration of GRP78 as an ER stress marker was measured with ELISA in mice treated with saline solution or Tm. In the saline-injected animals, no difference in renal GRP78 levels was noted between the WT and BDNF $^{(+/-)}$groups $(3.08 \pm 1.8$ and $2.94 \pm 1.1 \mathrm{ng} / \mathrm{mg}$ protein, respectively). As shown in Fig. 2, Tm caused a significant increase in the GRP78 kidney levels of both the wildtype $(6.24 \pm 1.9 \mathrm{ng} / \mathrm{mg}$ protein; $\mathrm{p}<0.05)$ and the BDNF heterozygous mice $(6.14 \pm 2.1 \mathrm{ng} / \mathrm{mg}$ protein; $\mathrm{p}<0.05)$. There was no significant difference between the WT+Tm and $\mathrm{BDNF}^{(+/-)}+$Tm groups (Fig. 2).

\section{Histological analysis}

The kidney tissue was examined histologically using H\&E staining to evaluate the effects of ER stress and BDNF deficiency. In comparison to the WT group, a slight deterioration in tubular structures and cells was observed in the kidney sections of the $\mathrm{BDNF}^{(+/)}$group. Tunicamycin injection caused a mild deterioration in the tubular structures of the kidneys of the WT+Tm group, while general tissue deterioration, pyknotic nucleus, and swollen cells were observed in the $\mathrm{BDNF}^{(+/)}+\mathrm{Tm}$ group (Fig. 3A-D).

\section{Renal apoptosis}

Apoptosis in kidney tissue was demonstrated with TUNEL immunohistochemical analysis; the results are presented in Fig. 4. The apoptotic index was $0.144 \pm 0.06$ and $0.476 \pm 0.19$ in the $\mathrm{WT}$ and $\mathrm{BDNF}^{(+/)}$groups, respectively. Tunicamycin-induced ER stress caused a significant increase in apoptosis in both the WT+Tm $(\mathrm{p}<0.01 \mathrm{vs}$ WT) and $\mathrm{BDNF}^{(+/-)}+\mathrm{Tm}(\mathrm{p}<0.001 \mathrm{vs} \mathrm{WT})$ groups. Apoptotic index was calculated as $1.636 \pm 0.96$ and $3.422 \pm 0.99$ for

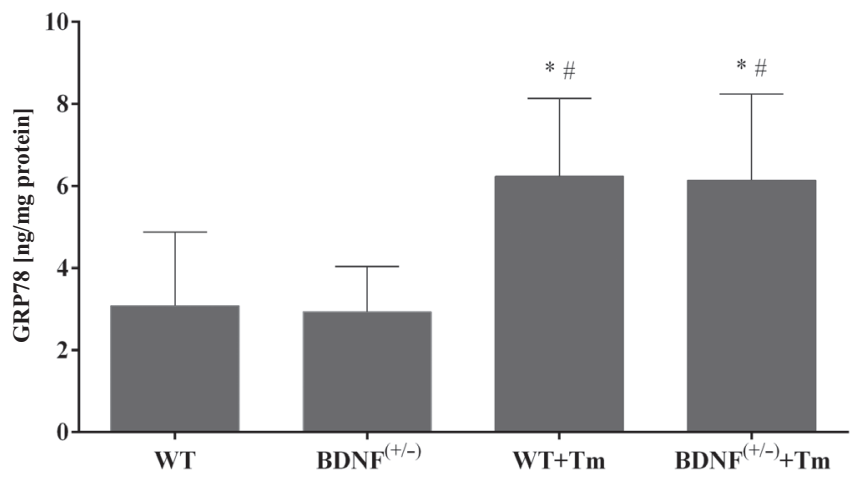

Fig. 2. GRP78 concentration in the kidneys of the $W T, B D N F^{(+/)}, W T+T m$, and $\mathrm{BDNF}^{(+/)}+\mathrm{Tm}$ groups. Data is presented as mean $\pm \mathrm{SD}(\mathrm{n}=7$ mice per group). ${ }^{*} p<0.05$ vs the WT group; $\# p<0.05$ vs the $B D N F^{(+/)}$group
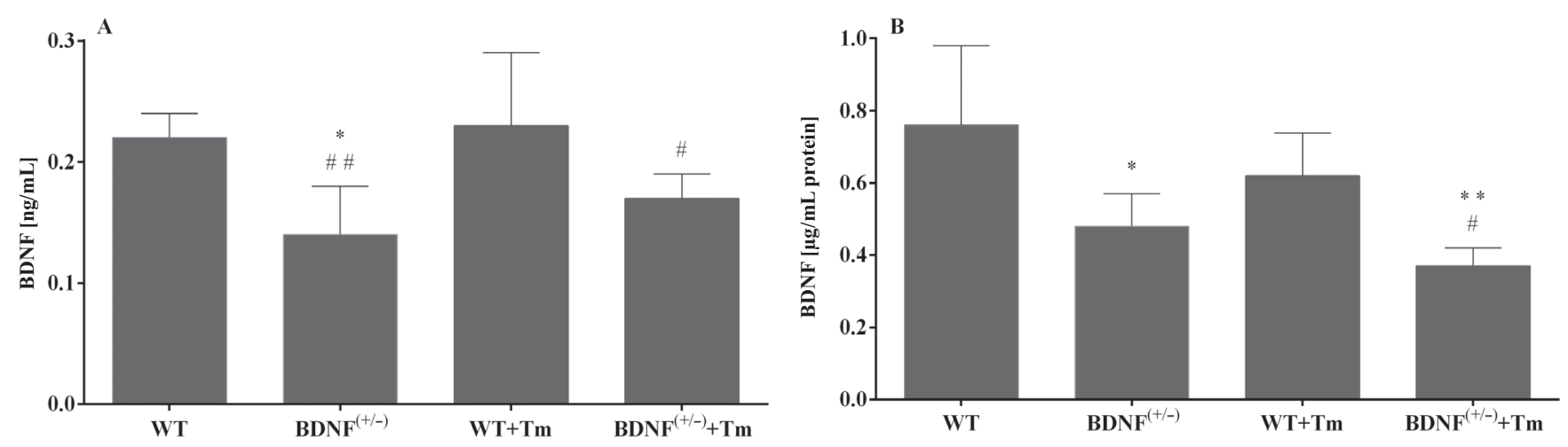

Fig. 1. BDNF level in serum (A) and kidney homogenates $(B)$ in the $W T, B D N F^{(+/)}, W T+T m$, and $B D N F^{(+/)}+T_{m}$ groups. Data is presented as mean $\pm S E(n=7$ mice per group). ${ }^{*} \mathrm{p}<0.05,{ }^{* *} \mathrm{p}<0.01$ vs the WT group; $\# \mathrm{p}<0.05, \# \# \mathrm{p}<0.01$ vs the WT+Tm group 


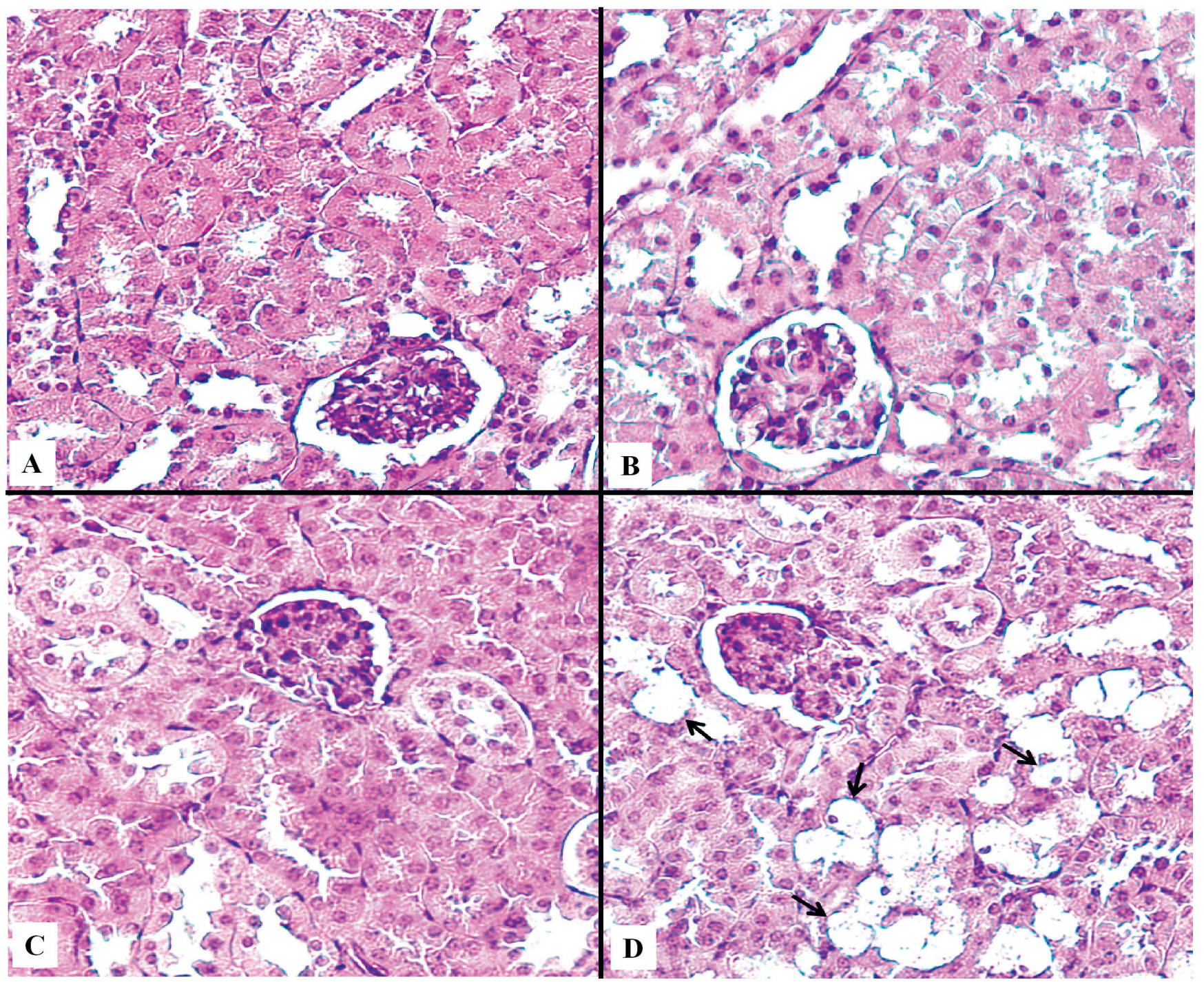

Fig. 3. Representative images of H\&E analysis (×20 magnification) of WT kidney tissue (A), BDNF(+/-) kidney tissue (B), WT+Tm kidney tissue (C) and $\mathrm{BDNF}^{(+/)}+\mathrm{Tm}(\mathrm{D})$ kidney tissue. Arrows indicate swollen cells

the $\mathrm{WT}+\mathrm{Tm}$ and $\mathrm{BDNF}^{(+/)}+\mathrm{Tm}$ groups, respectively. Tunicamycin-induced renal apoptosis was more pronounced in the $\mathrm{BDNF}^{(+/)}+\mathrm{Tm}$ group than in the $\mathrm{WT}+\mathrm{Tm}$ group $(\mathrm{p}<0.01)$.

\section{Caspase-12 level in kidney}

The caspase-12 levels in the kidney tissue were similar between the WT $(0.75 \pm 0.50 \mu \mathrm{g} / \mathrm{mg}$ of protein $)$ and $\mathrm{BDNF}^{(+/)}$groups $(0.71 \pm 0.63 \mu \mathrm{g} / \mathrm{mg}$ of protein). A single dose of Tm caused a significant increase in both the WT+Tm $(1.59 \pm 0.42 \mu \mathrm{g} / \mathrm{mg}$ of protein; $\mathrm{p}<0.05)$ and $\mathrm{BDNF}^{(+-)}+\mathrm{Tm}$ groups $(1.65 \pm 0.60 \mu \mathrm{g} / \mathrm{mg}$ of protein; $\mathrm{p}<0.05)$. This value was not statistically significant in the $\mathrm{WT}+\mathrm{Tm}$ group compared to the $\mathrm{BDNF}^{(+-)}+\mathrm{Tm}$ group.

\section{GADD153 immunohistochemistry}

Positive GADD153 staining was detected in all groups with weak to moderate positive cytoplasmic staining (intensity) in the glomeruli and tubule cells (Fig. 5). The proportion of immunopositively stained area for GADD153 was $7.55 \pm 1.41 \%$ and $7.84 \pm 1.20 \%$ in the WT and $\mathrm{BDNF}^{(+/)}$groups, respectively. Tm injection caused a significant increase in both the WT+Tm $(10.44 \pm 1.12 \%$; $\mathrm{p}<0.01)$ and $\mathrm{BDNF}^{(+/)}+\mathrm{Tm}$ groups $(12.35 \pm 1.30 \%$; $\mathrm{p}<0.001)$. GADD153 immunostaining was significantly higher in the $\mathrm{BDNF}^{(+/)}+\mathrm{Tm}$ group than in the $\mathrm{WT}+\mathrm{Tm}$ group $(\mathrm{p}<0.05)$.

\section{Serum creatinine}

Serum creatinine concentration was at a similar level in the WT and $\mathrm{BDNF}^{(+/)}$groups $(0.29 \pm 0.07 \mathrm{mg} / \mathrm{dL}$ and $0.31 \pm 0.06 \mathrm{mg} / \mathrm{dL}$, respectively). Creatinine levels were higher among Tm-injected animals: $0.40 \pm 0.06 \mathrm{mg} / \mathrm{dL}$ in the WT+Tm group $(\mathrm{p}<0.05)$ and $0.42 \pm 0.07 \mathrm{mg} / \mathrm{dL}$ in the $\mathrm{BDNF}^{(+-)}+\mathrm{Tm}$ group $(\mathrm{p}<0.05)$. There was no statistical difference between the $\mathrm{WT}+\mathrm{Tm}$ and $\mathrm{BDNF}^{(+/)}+\mathrm{Tm}$ groups. 

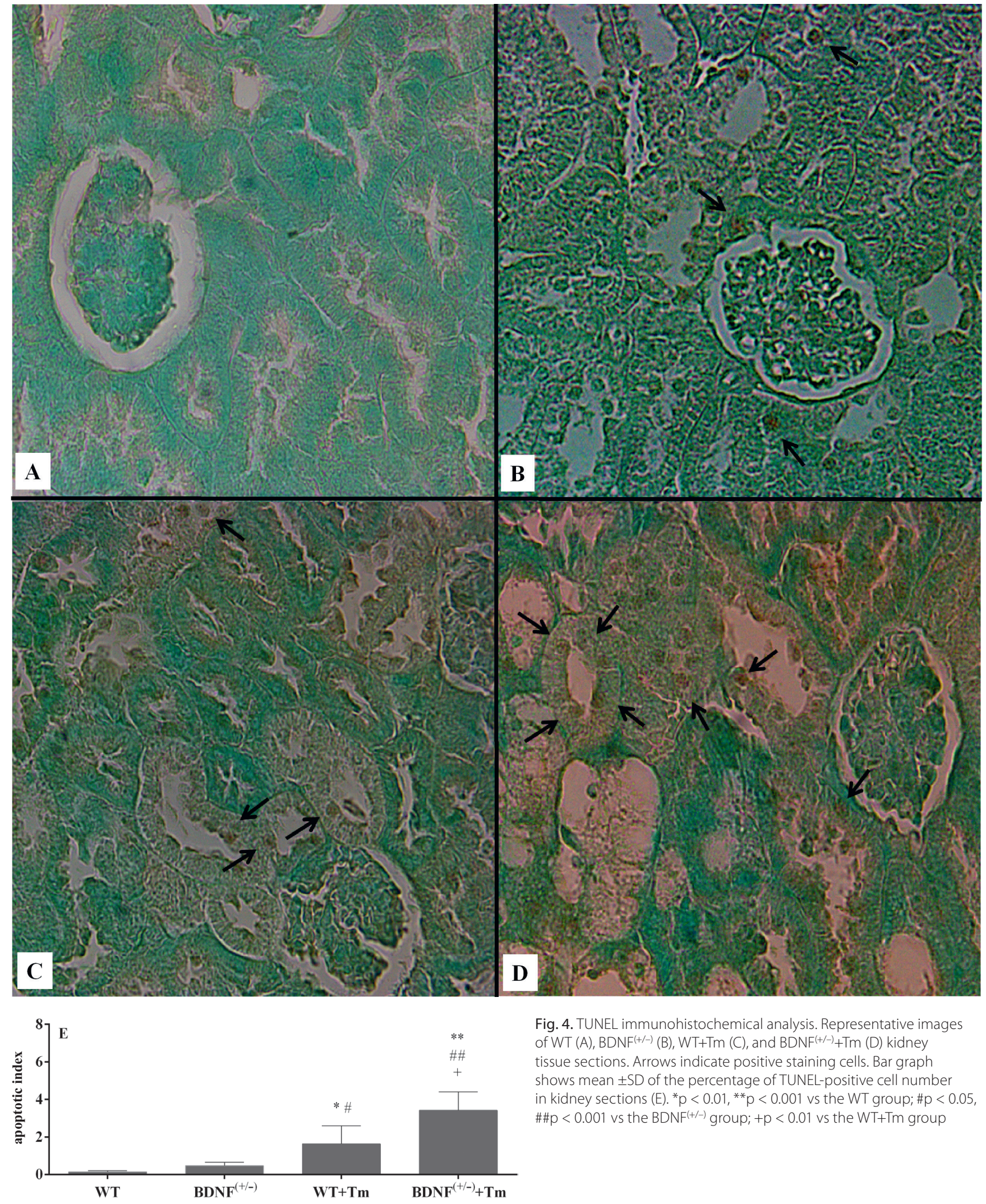

Fig. 4. TUNEL immunohistochemical analysis. Representative images of WT (A), BDNF(+/) $(\mathrm{B}), \mathrm{WT}+\mathrm{Tm}(\mathrm{C})$, and $\mathrm{BDNF}^{(+/)}+\mathrm{Tm}(\mathrm{D})$ kidney tissue sections. Arrows indicate positive staining cells. Bar graph shows mean $\pm \mathrm{SD}$ of the percentage of TUNEL-positive cell number in kidney sections (E). ${ }^{*} p<0.01,{ }^{* *} p<0.001$ vs the WT group; $\# p<0.05$, $\# \# p<0.001$ vs the $B D N F^{(+/)}$group; $+p<0.01$ vs the WT+Tm group

\section{The results of correlation analysis}

Correlation analysis showed a positive correlation between serum BDNF concentration and renal BDNF level $(\mathrm{r}=0.3909 ; \mathrm{p}<0.05)$. However, there is no correlation between serum BDNF levels and the other parameters studied. As shown in Fig. 6, there was a negative correlation between renal BDNF concentration and serum creatinine level, apoptotic index, and GADD153 immunostaining. 

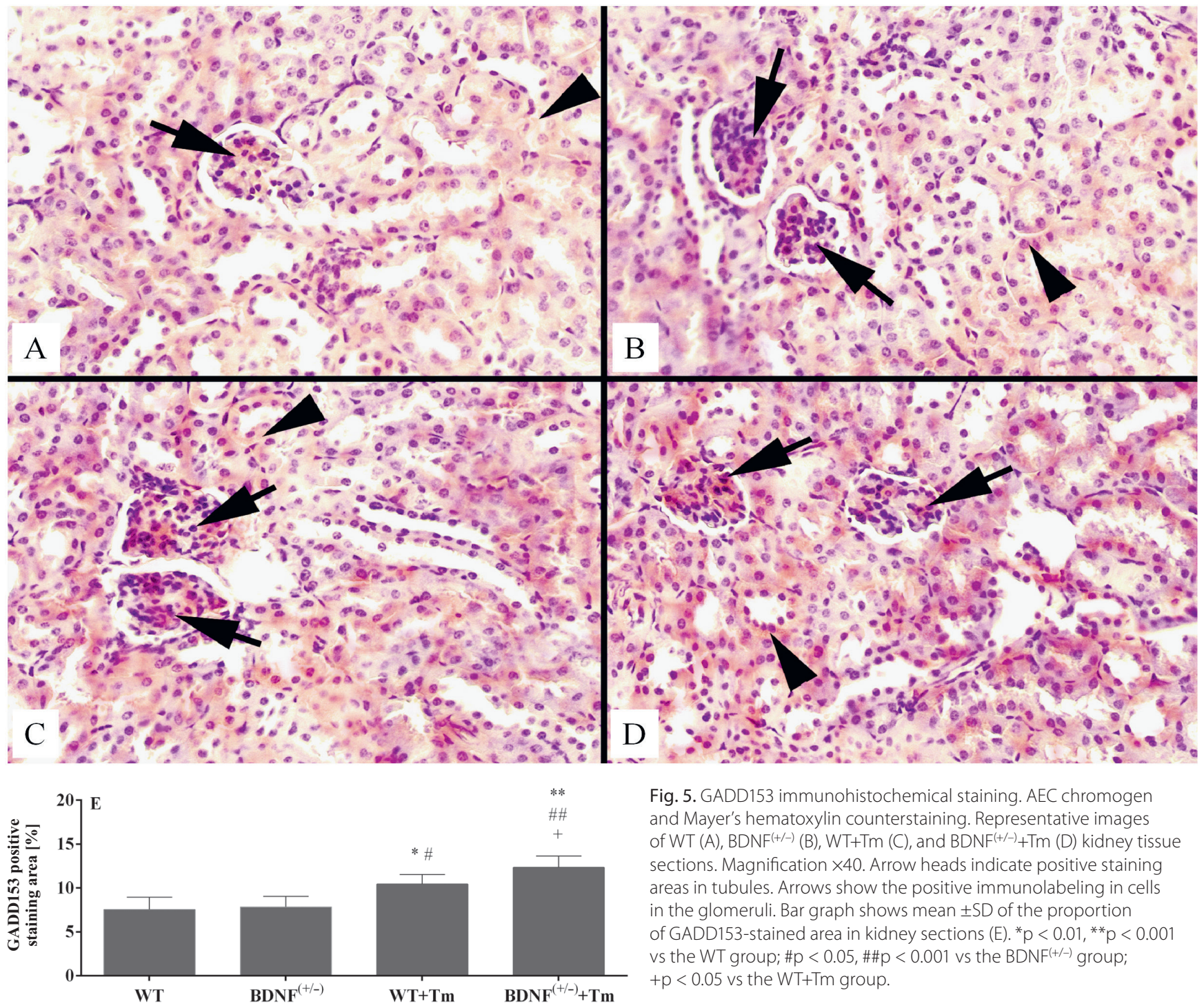

Fig. 5. GADD153 immunohistochemical staining. AEC chromogen and Mayer's hematoxylin counterstaining. Representative images of WT (A), BDNF(+t-) $(\mathrm{B}), \mathrm{WT}+\mathrm{Tm}(\mathrm{C})$, and $\mathrm{BDNF}^{(+/)}+\mathrm{Tm}(\mathrm{D})$ kidney tissue sections. Magnification $\times 40$. Arrow heads indicate positive staining areas in tubules. Arrows show the positive immunolabeling in cells in the glomeruli. Bar graph shows mean $+\mathrm{SD}$ of the proportion of GADD153-stained area in kidney sections (E). ${ }^{*} p<0.01$, ${ }^{* *} p<0.001$ vs the WT group; \#p $<0.05$, \#\#p $<0.001$ vs the $\mathrm{BDNF}^{(+)}$group $-p<0.05$ vs the WT+Tm group
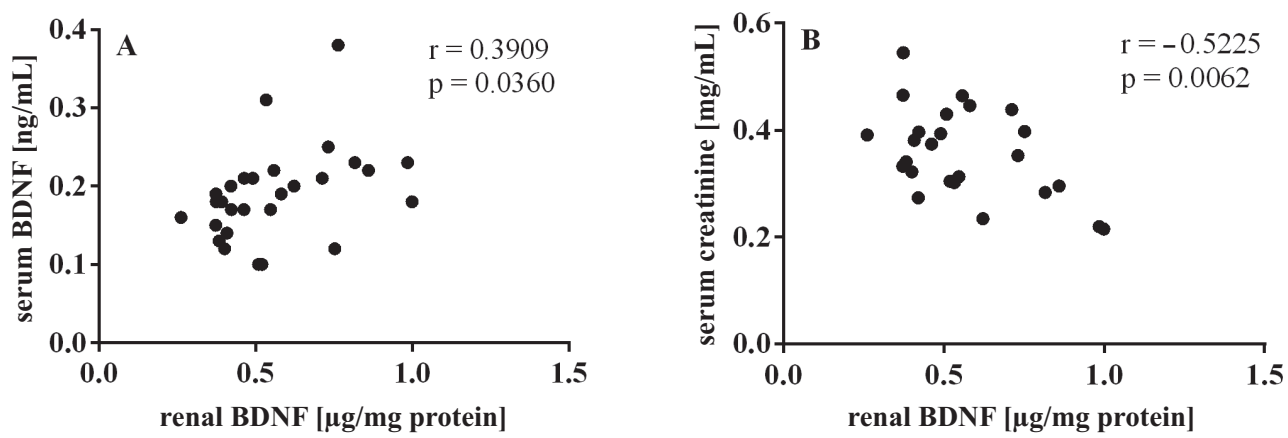

Fig. 6. Correlation between rena BDNF concentration and serum levels of BDNF (A), serum creatinine level (B), apoptotic index (C), and GADD153 immunostaining (D).
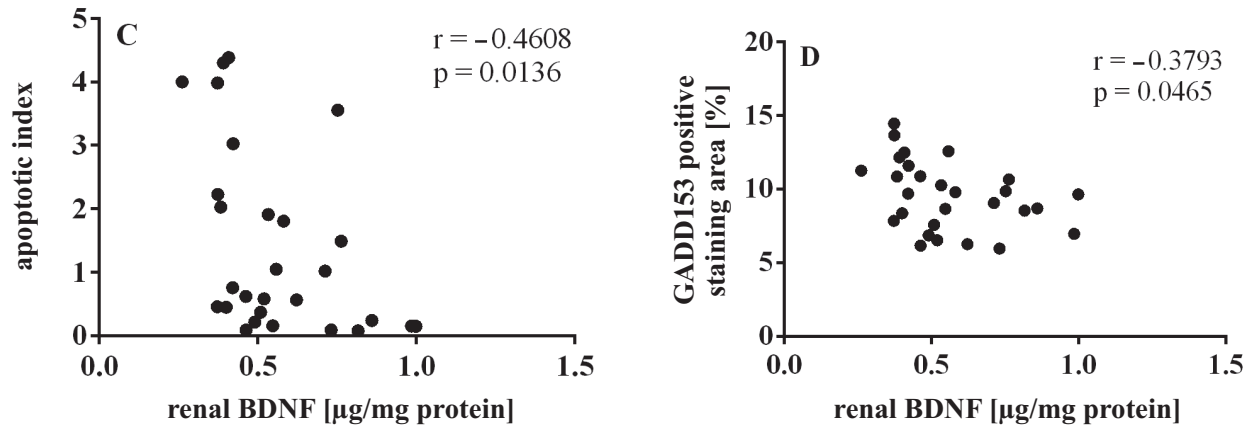


\section{Discussion}

The present study demonstrated that 1) chronic BDNF deficiency did not affect parameters of ER stress such as GRP78, caspase-12 and CHOP/GADD153 or apoptosis under baseline conditions, 2) chronic BDNF deficiency made kidneys more susceptible to ER stress-induced apoptosis, and 3) endogenously produced BDNF may have a protective effect in kidneys by suppressing the $\mathrm{CHOP} /$ GADD153 pathway, which mediates ER stress-induced apoptosis.

The transgenic animal model used in this study is characterized by a lack of 1 of the 2 alleles which code for BDNF, which results in reduced BDNF expression. In previous studies, lower expression of BDNF in both the brain and peripheral tissues (such as the heart and intestines) has been reported in $\mathrm{BDNF}^{(+/-)}$mice, as well as lower circulating BDNF levels. ${ }^{33-35}$ It is known that reduced BDNF levels induce hyperphagia, obesity, hyperglycemia, insulin resistance, and behavioral abnormalities (including increased aggression and hyperactivity) in these transgenic mice. ${ }^{36,37}$ In the present study, the presence of a transgene in each animal was confirmed using PCR in the tail tissue and chronic BDNF deficiency was confirmed with measurements of BDNF, showing significantly lower serum and tissue levels among the $\mathrm{BDNF}^{(+-)}$mice than in their wild-type littermates. Furthermore, increased food intake, body weight, aggression, and fat mass were observed in $\mathrm{BDNF}^{(+/-)}$mice during the experiments (data not shown).

The endoplasmic reticulum stress refers to physiological or pathological states such as oxidative stress, hypoxia and energy depletion which result in the accumulation of misfolded or unfolded proteins in the ER lumen., ${ }^{1,2}$ As the ER stress-induced tissue injury has been implicated in a variety of diseases, ER research is attracting more and more attention. Tunicamycin, thapsigargin and brefeldin A are defined as ER stress-inducing agents with different mechanisms of action. ${ }^{38}$ Tunicamycin induces ER stress by inhibiting N-linked glycosylation and can be used in both in vivo and in vitro studies. ${ }^{18,20,30,31}$ Previous studies reported increased GRP78 levels in kidneys following Tm-induced renal ER stress, as well as reduced renal function after $1-5$ days of Tm injection. ${ }^{30,31}$ In the present study, comparing to the saline injected control groups, renal GRP78 levels found to be increased in both wild-type and BDNF heterozygous mice after 3 days of Tm injection. Furthermore, in accordance with previous studies, higher creatinine levels were detected in serum samples, signifying reduced renal function.

The results of our BDNF assays showed that Tm-induced ER stress did not alter serum or renal BDNF levels. Since BDNF is a secretory protein, a decrease in BDNF levels can be expected during ER dysfunction. Indeed, Wei et al. demonstrated that homocysteine-induced ER stress modeling was associated with a decrease in BDNF expression as well as increased ER stress in the hippocampus following
7 days of intracerebroventricular homocysteine administration. ${ }^{39}$ Although there is no study in the literature to compare our results with, we propose that the short duration of the experiment (3 days) may have been insufficient for such an effect.

During ER stress, UPR can lead to cell repair and survival through the upregulation of ER chaperones and the global attenuation of protein synthesis, both of which result in a reduction of unfolded protein load in the ER lumen. ${ }^{2-4}$ However, when ER functions are critically impaired, apoptosis can be triggered in order to protect the organism by eliminating the damaged cells. It has been reported that at least 3 pathways are involved in ER stress-induced apoptosis: transcriptional activation of CHOP/GADD153, activation of the JNK pathway and caspase- $12 .{ }^{5}$

In this study, ER stress-induced apoptosis was proven by the increased apoptotic index in the Tm-injected mice. Although there were no differences in renal GRP78 levels between the $\mathrm{WT}+\mathrm{Tm}$ and $\mathrm{BDNF}^{(+/)}+\mathrm{Tm}$ groups, apoptosis was more prominent in the BDNF-deficient animals. Furthermore, histological analysis of the renal sections revealed that the kidneys in the BDNF-deficient mice were more susceptible to Tm-induced tissue injury. These results may point to a protective role of endogenous BDNF against ER stress-induced apoptosis and renal injury. In previous studies, the protective effect of BNDF has been shown in neuronal tissue and endometrial epithelial cells during ER stress ${ }^{18-20}$ as well as in adriamycin-induced nephropathy. ${ }^{21}$ Although ER stress-induced apoptosis was greater in BDNF-deficient mice, the serum creatinine levels (an indicator for renal function) in these mice were not different from those of the WT+Tm group. Nevertheless, a negative correlation between renal BDNF expression and serum creatinine concentration suggests that BDNF may also be important in terms of renal function. The effect of BDNF would be important in preserving kidney function in renal diseases involving ER stress. It has been reported that baseline serum BDNF levels were significantly lower in hemodialysis patients than in the age-matched control group. ${ }^{40}$ This finding is also consistent with the study by Kurajoh et al., in which serum BDNF levels were lower in patients with chronic kidney disease. ${ }^{17}$ Considering the contribution of ER stress to deteriorating kidney function in chronic kidney disease, ${ }^{23,24}$ it can be suggested that in patients with both chronic ER stress and BDNF deficiency, renal function would be more vulnerable.

The molecular mechanisms involved in the protective effects of BDNF against ER stress have been studied in neuronal cells. Shimoke et al. revealed that BDNF prevents ER stress-induced apoptosis by suppressing the activation of caspase-12 through a phosphatidylinositol 3-kinase (PI3-K) dependent mechanism, while Chen et al. suggested that the suppression of CHOP activation contributes to BDNF-mediated neuroprotection during ER stress. ${ }^{18,19}$ In the present study, caspase-12 and GADD153 levels were measured in renal tissue and our results showed 
that Tm administration significantly increased caspase-12 and GADD153 levels in both wild-type and BDNF heterozygous mice. Although the Tm-induced increase of caspase-12 levels were similar in both groups, the increase in GADD153 was greater in the BDNF heterozygous mice than the wild-type ones. These results suggest the possibility that endogenous BDNF could protect kidneys against ER stress-induced apoptosis by reducing the GADD153 increase.

The role of the CHOP/GADD153 pathway in Tm-induced renal damage has been demonstrated in both in vitro and in vivo studies. Carlisle et al. have shown that a siRNAmediated inhibition of CHOP expression significantly reduced Tm-induced apoptosis in HK-2 cells (a cell model of human renal proximal epithelial cells). ${ }^{41}$ The same study concluded that Tm-induced renal damage was less pronounced in $\mathrm{CHOP}^{-/-}$mice than in their wild-type littermates. ${ }^{41}$ The positive correlation between GADD153 staining and renal apoptotic index in our study is consistent with previous findings. Additionally, the negative correlation between GADD153 and renal BDNF concentration and the higher expression of GADD153 during ER stress in the BDNF-deficient group both suggest the possibility that the protective effect of BDNF on ER stress-induced renal injury may be related to GADD153 expression.

As a result, this study showed that endogenous BDNF may play a protective role in kidneys against ER stressinduced apoptosis through the suppression of CHOP/ GADD153. BDNF concentration could be associated with kidney function/kidney diseases. Patients with kidney disease might be examined for BDNF deficiency. Although further studies are needed, BDNF and its signaling pathways can be considered to have potential for protective/ therapeutic strategies.

\section{References}

1. Xu C, Bailly-Maitre B, Reed JC. Endoplasmic reticulum stress: Cell life and death decisions. J Clin Invest. 2005;115:2656-2664.

2. Zhang K, Kaufman RJ. The unfolded protein response: A stress signaling pathway critical for health and disease. Neurology. 2006;66: S102-S109.

3. Cao SS, Kaufman RJ. Unfolded protein response. Curr Biol. 2012;22(16): R622-626.

4. Breckenridge DG, Germain M, Mathai JP, Nguyen M, Shore GC. Regulation of apoptosis by endoplasmic reticulum pathways. Oncogene. 2003;22(53):8608-8618.

5. Oyadomari S, Mori M. Roles of CHOP/GADD153 in endoplasmic reticulum stress. Cell Death Differ. 2004;11:381-389.

6. Yoshida H. ER stress and diseases. FEBS J. 2007;274:630-658.

7. Vidal RL, Hetz C. Crosstalk between the UPR and autophagy pathway contributes to handling cellular stress in neurodegenerative disease. Autophagy. 2012;8(6):970-972.

8. Ogawa S, Kitao Y, Hori O. Ischemia-induced neuronal cell death and stress response. Antioxid Redox Signal. 2007;9:573-587.

9. Cunard R. Endoplasmic reticulum stress in the diabetic kidney: The good, the bad and the ugly. J Clin Med. 2015;4(4):715-740.

10. Binder DK, Scharfman HE. Brain-derived neurotrophic factor. Growth Factors. 2004;22(3):123-131.

11. Shibayama E, Koizumi H. Cellular localization of the Trk neurotrophin receptor family in human non-neuronal tissues. Am J Pathol. 1996; 148(6):1807-1818.
12. Yamamoto M, Sobue G, Yamamoto K, Terao S, Mitsuma T. Expression of mRNAs for neurotrophic factors (NGF, BDNF, NT-3, and GDNF) and their receptors (p75NGFR, trkA, trkB, and trkC) in the adult human peripheral nervous system and nonneural tissues. Neurochem Res. 1996;21(8):929-938.

13. Lommatzsch M, Braun A, Mannsfeldt A, et al. Abundant production of brain-derived neurotrophic factor by adult visceral epithelia. Am J Pathol. 1999;155(4):1183-1193.

14. Krabbe KS, Nielsen AR, Krogh-Madsen R, et al. Brain-derived neurotrophic factor (BDNF) and type 2 diabetes. Diabetologia. 2007;50(2): 431-438.

15. Manni L, Nikolova V, Vyagova D, Chaldakov GN, Aloe L. Reduced plasma levels of NGF and BDNF in patients with acute coronary syndromes. Int J Cardiol. 2005;102(1):169-171.

16. Polyakova M, Stuke K, Schuemberg K, Mueller K, Schoenknecht P, Schroeter ML. BDNF as a biomarker for successful treatment of mood disorders: A systematic \& quantitative meta-analysis. J Affect Disord. 2015;174:432-440.

17. Kurajoh $M$, Kadoya $M$, Morimoto $A$, et al. Plasma brain-derived neurotrophic factor concentration is a predictor of chronic kidney disease in patients with cardiovascular risk factors - Hyogo Sleep Cardio-Autonomic Atherosclerosis study. PLoS One. 2017;12(6): e0178686.

18. Chen G, Fan Z, Wang X, et al. Brain-derived neurotrophic factor suppresses tunicamycin-induced upregulation of $\mathrm{CHOP}$ in neurons. J Neurosci Res. 2007;85(8):1674-1684.

19. Shimoke K, Utsumi T, Kishi S, et al. Prevention of endoplasmic reticulum stress-induced cell death by brain-derived neurotrophic factor in cultured cerebral cortical neurons. Brain Res. 2004;1028(1): 105-111.

20. Lim W, Bae H, Bazer FW, Song G. Brain-derived neurotrophic factor improves proliferation of endometrial epithelial cells by inhibition of endoplasmic reticulum stress during early pregnancy.J Cell Physiol. 2017. doi:10.1002/jcp. 25834

21. Li M, Armelloni S, Zennaro C, et al. BDNF repairs podocyte damage by microRNA-mediated increase of actin polymerization. J Pathol. 2015;235(5):731-744.

22. García-Suárez O, González-Martínez T, Germana A, et al. Expression of TrkB in the murine kidney. Microsc Res Tech. 2006;69(12):1014-1020.

23. Inagi R. Endoplasmic reticulum stress in the kidney as a novel mediator of kidney injury. Nephron Exp Nephrol. 2009;112(1):e1-9.

24. Maekawa H, Inagi R. Stress signal network between hypoxia and ER stress in chronic kidney disease. Front Physiol. 2017;8:74.

25. Cybulsky AV, Takano T, Papillon J, Bijian K. Role of the endoplasmic reticulum unfolded protein response in glomerular epithelial cell injury. J Biol Chem. 2005;280:24396-24403.

26. Lindenmeyer MT, Rastaldi MP, Ikehata M, et al. Proteinuria and hyperglycemia induce endoplasmic reticulum stress. J Am Soc Nephrol. 2008;19:2225-2236.

27. Ohse T, Inagi R, Tanaka T, et al. Albumin induces endoplasmic reticulum stress and apoptosis in renal proximal tubular cells. Kidney Int. 2006;70:1447-1455.

28. Korte M, Carroll P, Wolf E, Brem G, Thoenen H, Bonhoeffer T. Hippocampal long-term potentiation is impaired in mice lacking brainderived neurotrophic factor. Proc Natl Acad Sci U S A. 1995;92(19): 8856-8860.

29. Abidin I, Yildirim M, Aydin-Abidin S, et al. Penicillin-induced epileptiform activity and EEG spectrum analysis of BDNF heterozygous mice: An in vivo electrophysiological study. Brain Res Bull. 2011;86(3-4): 159-164.

30. De Miguel C, Hamrick WC, Hobbs JL, Pollock DM, Carmines PK, Pollock JS. Endothelin receptor-specific control of endoplasmic reticulum stress and apoptosis in the kidney. Sci Rep. 2017;7:43152.

31. Hodeify R, Megyesi J, Tarcsafalvi A, et al. Gender differences control the susceptibility to ER stress-induced acute kidney injury. Am J Physiol Renal Physiol. 2013;304(7):F875-882.

32. CirrikS, Yavuzer BU, Oner G. Exercise-induced changes in renal URAT1 activity and expression in rats. Ren Fail. 2010;32(7):855-862.

33. Kernie SG, Liebl DJ, Parada LF. BDNF regulates eating behavior and locomotor activity in mice. EMBO J. 2000;19(6):1290-1300.

34. Chen FX, Yu YB, Yuan XM, Zuo XL, Li YQ. Brain-derived neurotrophic factor enhances the contraction of intestinal muscle strips induced by SP and CGRP in mice. Regul Pept. 2012;178(1-3):86-94. 
35. Halade GV, Ma Y, Ramirez TA, et al. Reduced BDNF attenuates inflammation and angiogenesis to improve survival and cardiac function following myocardial infarction in mice. Am J Physiol Heart Circ Physiol. 2013;305(12):H1830-1842.

36. Lyons WE, Mamounas LA, Ricaurte GA, et al. Brain-derived neurotrophic factor-deficient mice develop aggressiveness and hyperphagia in conjunction with brain serotonergic abnormalities. Proc Natl Acad Sci U S A. 1999;96(26):15239-15244.

37. Duan W, Guo Z, Jiang H, Ware M, Mattson MP. Reversal of behavioral and metabolic abnormalities, and insulin resistance syndrome, by dietary restriction in mice deficient in brain-derived neurotrophic factor. Endocrinology. 2003;144(6):2446-2453.
38. Samali A, Fitzgerald U, Deegan S, Gupta S. Methods for monitoring endoplasmic reticulum stress and the unfolded protein response. Int J Cell Biol. 2010;2010:830307.

39. Wei HJ, Xu JH, Li MH, et al. Hydrogen sulfide inhibits homocysteineinduced endoplasmic reticulum stress and neuronal apoptosis in rat hippocampus via upregulation of the BDNF-TrkB pathway. Acta Pharmacol Sin. 2014;35(6):707-715.

40. Zoladz JA, Śmigielski M, Majerczak J, et al. Hemodialysis decreases serum brain-derived neurotrophic factor concentration in humans. Neurochem Res. 2012;37(12):2715-2724.

41. Carlisle RE, Brimble E, Werner KE, et al. 4-Phenylbutyrate inhibits tunicamycin-induced acute kidney injury via CHOP/GADD153 repression. PLoS One. 2014;9(1):e84663. 